\title{
GMR
}

\section{RNA-Seq-based transcriptome and the reproduction-related genes for the aphid Schlechtendalia chinensis (Hemiptera, Aphididae)}

\author{
P. Liu ${ }^{1,2,3}$, Z.X. Yang ${ }^{1,2}$, X.M. Chen ${ }^{1,2}$ and P. Yang ${ }^{1,2}$ \\ ${ }^{1}$ Research Institute of Resource Insects, Chinese Academy of Forestry, \\ Kunming, Yunnan, China \\ ${ }^{2}$ Key Laboratory of Breeding and Utilization of Resource Insects of State \\ Forestry Administration, Kunming, Yunnan, China \\ ${ }^{3}$ Yunnan Forestry Technological College, Kunming, Yunnan, China \\ Corresponding author: Z.X. Yang \\ E-mail: yzx1019@163.com
}

Genet. Mol. Res. 16 (1): gmr16019448

Received October 18, 2016

Accepted December 5, 2016

Published March 22, 2017

DOI http://dx.doi.org/10.4238/gmr16019448

Copyright (C) 2017 The Authors. This is an open-access article distributed under the terms of the Creative Commons Attribution ShareAlike (CC BY-SA) 4.0 License

\begin{abstract}
Chinese galls form on sumac plants (Rhus chinensis) and are used for medicinal and chemical purposes, due to their richness in tannins. The galls are formed by aphids, the most prominent of which is Schlechtendalia chinensis, which forms horn-shaped galls on the winged rachis of $R$. chinensis. S. chinensis has a complex life cycle, including both $R$. chinensis and certain mosses as hosts, as well as the existence of both sexual and asexual reproduction (cyclical parthenogenesis). Previous studies have shown that the alternate occurrence of sexual and asexual reproduction relies on many environmental factors, such as temperature, photoperiod, and host-plant. However, the sexual and asexual modes of reproduction are poorly understood on the molecular level. We aimed to
\end{abstract}

Genetics and Molecular Research 16 (1): gmr16019448 
identify genes that respond to changes in temperature that may be related to the reproduction process. We compared the transcriptome of two samples of $S$. chinensis, which had been reared at different temperatures. Using gene ontology analysis, a total of 51 evolutionary conserved genes related to reproduction determination in insects were identified. Of these genes, S. chinensis harbors 42 genes. When we analyzed aphids that had asexually or sexually produced offspring, eight out of these 42 genes were identified and expressed differently in two temperature conditions. This is the first report on genes associated with reproduction determination in $S$. chinensis, which has a complex life cycle. Genes, expressed differently in response to different temperature conditions will be helpful to understand the mechanism of aphid reproductive determination.

Key words: RNA-seq; Transcriptome; Reproduction-related gene; Horned gall aphid; Schlechtendalia chinensis

\section{INTRODUCTION}

Chinese galls are abnormal growths of plant tissue induced by some aphids belonging to the tribe Fordini (Eriosomatinae, Aphididae). Among these aphids, eleven species form galls on Rhus trees. These species are mainly distributed in East Asia, especially in southwest China. The galls have been used for medicinal and chemical purposes, as they are rich in tannins that account for about $60-70 \%$ of total dry weight. The galls are most often used as a source of tannic, gallic, and pyrogallic acids (Zhang, 1987). Schlechtendalia chinensis, the best-studied gall-producing aphid, induces sealed horn-shaped galls on the winged rachis of $R$. chinensis. The horned galls account for about $75 \%$ of Chinese gall production (Tang and Cai, 1957).

S. chinensis has a complex life cycle that includes two different hosts. In the early spring, alate sexuparae fly to the trunk of their primary host-plant $R$. chinensis, to asexually produce sexual females and males that mate to produce fundatrices ovoviviparously. The fundatrices crawl to and feed on the tender leaves and initiate gall formation (Zhang and Zhong, 1983). The fundatrices reproduce parthenogenetically for three generations within a gall. Usually each gall is induced by a single fundatrix. After the gall matures and dehisces in autumn, the third alate fundatrigeniae migrate from the gall to their secondary host; mosses. There, they asexually produce larvae that live in the tender stem of mosses and excrete wax to envelop themselves for overwintering. The following spring, the larvae molt and form alate sexuparae, which then fly back to $R$. chinensis and start the next life cycle (Zhang et al., 1999; Shao et al., 2013; Liu et al., 2014).

The alternation of sexual and asexual reproduction (cyclical parthenogenesis) is mainly influenced by temperature, which plays an important role for aphid polymorphism (Dixon, 1973; Lamb, 1992; Artacho et al., 2011). Zhang et al. (1993) found that all overwintering larvae of $S$. chinensis developed into alate sexuparae followed by production of males and females when they were reared at $4.5^{\circ} \mathrm{C}$. However, all larva developed to apterous larvae followed by parthenogenetic reproduction on mosses when they were reared at $22^{\circ} \mathrm{C}$ (Zhang et al., 1993). By contrast, the larva developed into alate sexuparae and apterous larvae at different ratios, when reared at $4.5^{\circ}-18^{\circ} \mathrm{C}$ (Zhang et al., 1993).

RNA sequencing (RNA-Seq) is important for microarray and quantitative real-time polymerase chain reaction (qRT-PCR) techniques (Malone and Oliver, 2011; Ozsolak and

Genetics and Molecular Research 16 (1): gmr16019448 
Milos, 2011). It covers a broad range of transcript abundances and has been applied to a wide range of species including human, mouse, yeast, and some plant species (Nagalakshmi et al., 2008; Sultan et al., 2008; Koenig et al., 2013). Herein, we applied RNA-Seq to construct cDNA libraries to analyze the global transcriptome of S. chinensis. This was done to identify differentially expressed transcripts between two samples that differed only with respect to the temperature at which they had been reared. In addition, we selected some genes related to sex determination from other insects, to compare and analyze with our unigenes. A preliminary analysis of sex determination of $S$. chinensis was performed.

\section{MATERIAL AND METHODS}

\section{Host-plant and aphid production}

In August 2013, the winter host moss, Plagiomnium maximoviczii (Lindb.) T. Kop., was cultivated in plastic trays $(30 \times 20 \times 3 \mathrm{~cm}$, with $2 \mathrm{~cm}$ loose loam) in a greenhouse at Kunming, Yunnan Province, Southwest China. Conventional management was carried out, in order to avoid disease and pest infestation.

In the same autumn, mature horned galls were collected from the field and moved to the moss nursery. Alate fundatrigeniae were allowed to migrate from the gall dehiscence to the mosses and to asexually produce larvae on the tender stems. After a few days, when the larvae were observed to excrete white wax to envelop themselves, all trays were transferred to an incubator kept at $75 \%$ relative humidity and 13L:11D photoperiod. Three constant temperatures, 7.5, 18 and $22^{\circ} \mathrm{C}$, respectively, were used (Zhang et al., 1993). About 1000 aphid individuals were included in each treatment.

After 40 days, 150 aphid larvae were collected from each treatment and stored at $-70^{\circ} \mathrm{C}$ in Trizol (Invitrogen, Carlsbad, California, USA). The rest of the aphids were left to overwinter until next spring. At this point, their eclosion rates at the three different temperatures were measured. The aphid samples reared at $7.5^{\circ}$ and $18^{\circ} \mathrm{C}$ were named LA (low temperature) and HA (high temperature), respectively. And the aphids stored in Trizol from the LA and HA treatments were used for further RNA analysis.

\section{RNA-Seq, clustering, and transcriptome assembly}

Total aphid RNA was isolated using the Trizol kit (Invitrogen) and submitted to Novogene (Beijing, China) for RNA-Seq analysis. RNA purity was examined using a NanoPhotometer ${ }^{\mathbb{B}}$ spectro photometer (IMPLEN, Westlake Village, CA, USA) and degradation and contamination was investigated on a $1 \%$ agarose gel. RNA concentration was measured using Qubit ${ }^{\circledR}$ RNA Assay Kit in a Qubit ${ }^{\circledR}$ 2.0 Flurometer (Life Technologies, Carlsbad, CA, USA). Sequencing libraries were generated using NEBNext ${ }^{\mathbb{B}}$ Ultra $^{\mathrm{TM}}$ Directional RNA Library Prep Kit for Illumina ${ }^{\circledR}$ (NEB, Beverly, MA, USA) following the manufacturer recommendations. Index codes were used to attribute sequences to each sample. Finally, products were purified using the AMPure XP system (Beckman Coulter, Beverly, MA, USA) and library quality was assessed on the Agilent Bioanalyzer 2100 system.

Clustering of the index-coded samples was performed on a cBot Cluster Generation System using TruSeq PE Cluster Kit v3-cBot-HS (Illumina, USA) according to the manufacturer instructions. After cluster generation, the library preparations were sequenced on an Illumina

Genetics and Molecular Research 16 (1): gmr16019448 
HiSeq 2000 platform and paired-end reads were generated. Finally, the transcriptome assembly was accomplished using Trinity (Grabherr et al., 2011) with min_kmer_cov set to 2 and all other parameters set to default.

\section{Gene annotation and functional classification}

Gene function was annotated using the following databases: $\mathrm{Nr}$ (NCBI non-redundant protein sequences), Nt (NCBI non-redundant nucleotide sequences), Pfam (Protein family), KOG (euKaryotic Orthologous Groups), Swiss-Prot (a manually annotated and reviewed protein sequence database), KO (KEGG Ortholog database), and GO (Gene Ontology). The GO enrichment analysis of differentially expressed genes (DEGs) was implemented using GOseq R package based on Wallenius non-central hyper-geometric distribution (Young et al., 2010), which can adjust for length biases in the DEGs. KEGG (Kanehisa et al., 2008) is a database resource for understanding high-level functions and utilities of the biological system, such as the cell, organism, and ecosystem, from molecular-level information, especially large-scale molecular datasets generated by genome sequencing and other high-throughput experimental technologies (http://www.genome.jp/kegg/). KOBAS (Mao et al., 2005) software was used to test the statistical enrichment of DEGs in the KEGG pathways.

\section{Gene expression analysis}

Quantification of transcript levels was estimated by RSEM (Li and Dewey, 2011). For each sample: 1) clean data were mapped back onto the assembled transcriptome; 2) a read count for each gene was obtained from the mapping results. A differential expression analysis of two samples was performed using the DESeq R package (1.10.1). DESeq provides statistical routines for determining differential expression in digital gene expression data, using a model based on the negative binomial distribution. The resulting $\mathrm{P}$ values were adjusted using the BenjaminiHochberg approach for controlling false discovery rates (Benjamini and Hochberg, 1995). Genes with an adjusted $\mathrm{P} \leq 0.05$ found by DESeq were assigned as differentially expressed.

\section{qRT-PCR analysis}

Total RNA of each sample was reverse-transcribed in a $20-\mathrm{mL}$ reaction system according to the protocol provided with the M-MLV first strand kit (Invitrogen, Carlsbad, California, USA). A total of 12 genes, identified as being differently expressed in this study, were selected for qRT-PCR analysis. EvaGreen (Bio-RAD, California, USA) was used as DNA-binding fluorescent dye, and tubulin was used as internal standard. The absolute concentrations of target genes in two samples were determined using the standard curve quantitative method and the statistical analyses were performed using the least significant difference test at $\mathrm{P}=0.01$ using SPSS statistical software.

\section{RESULTS}

\section{Offspring differentiation and eclosion rates of overwintering larvae}

The results of offspring differentiation and eclosion rates of overwintering larvae 
reared at different temperatures indicated that 1 ) at $7.5^{\circ} \mathrm{C}, 241$ alate sexuparae migrated, 28 remained in the mosses, and the eclosion rate was $89.6 \%$. All emigrants produced sexual male and female. 2) At $18^{\circ} \mathrm{C}$, only 6 alate sexuparae migrated and 107 remained in the mosses. The eclosion rate was $5.3 \%$. 3) At $22^{\circ} \mathrm{C}$, no alate sexuparae migrated, instead all continued reproducing parthenogenetically in the mosses.

\section{Transcriptome sequencing and assembly}

The Illumina sequencing data of $S$. chinensis generated 126,726,344 raw reads. After removing adapter sequences, ambiguous nucleotides, and low-quality sequences, 122,039,510 clean reads remained. The mean read length was $666 \mathrm{bp}$. All clean reads were assembled into 84,280 unigenes that ranged from 201 to $23,871 \mathrm{bp}$ with an N50 length of $1073 \mathrm{bp}$.

\section{Functional annotation and pathway assignment}

All assembled unigenes were annotated against the sequences in $\mathrm{Nr}, \mathrm{Nt}, \mathrm{KO}$, SwissProt, Pfam, GO, and KOG databases. In the Nr protein database, 24,948 genes were annotated, which accounted for $29.6 \%$ of all assembled unigenes. In all databases, 4403 $(5.22 \%)$ unigenes were annotated and 34,753 (41.23\%) unigenes were annotated in at least one database (Table 1). According to GO, 28,484 non-redundant unigenes were classified into three major functional categories (biological process, cellular component, and molecular function) and 54 subcategories (Figure 1).

Table 1. Annotation statistics of all assembled unigenes from Nr, Nt, KO, SwissProt, Pfam, GO, and KOG.

\begin{tabular}{l|c|c}
\hline Annotated & Number of Unigenes & NPercentage (\%) \\
\hline $\mathrm{Nr}$ & 24,948 & 29.6 \\
\hline $\mathrm{Nt}$ & 10,702 & 12.69 \\
\hline $\mathrm{KO}$ & 11,747 & 23.93 \\
\hline SwissProt & 19,630 & 31.05 \\
\hline PFAM & 26,170 & 33.79 \\
\hline $\mathrm{GO}$ & 28,484 & 19.39 \\
\hline KOG & 16,346 & 5.22 \\
\hline all Databases & 4,403 & 41.23 \\
\hline at least one Database & 34,753 & 100 \\
\hline Total Unigenes & 84,280 & \\
\hline
\end{tabular}

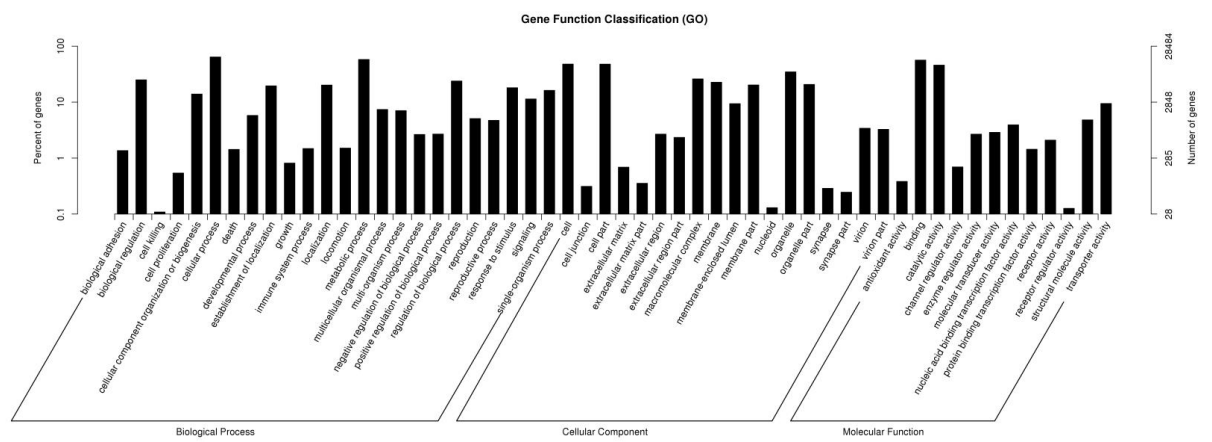

Figure 1. GO categories of 28,484 non-redundant unigenes. The right y-axis indicates the number of genes in each category, whereas the left y-axis indicates the percentage of a specific gene subcategory within each main category. 
To classify orthologous gene products, 16,346 (19.39\%) non-redundant unigenes were subdivided into $26 \mathrm{KOG}$ classifications. Among these, the cluster of 'general function prediction' $(2700,16.52 \%)$ represented the largest group, followed by 'signal transduction' $(1859,11.37 \%)$ and 'post-translational modification, protein turnover, chaperone' (1853, $11.34 \%)$, whereas 'unnamed protein' $(5,0.03 \%)$ was the smallest group (Figure 2$)$.

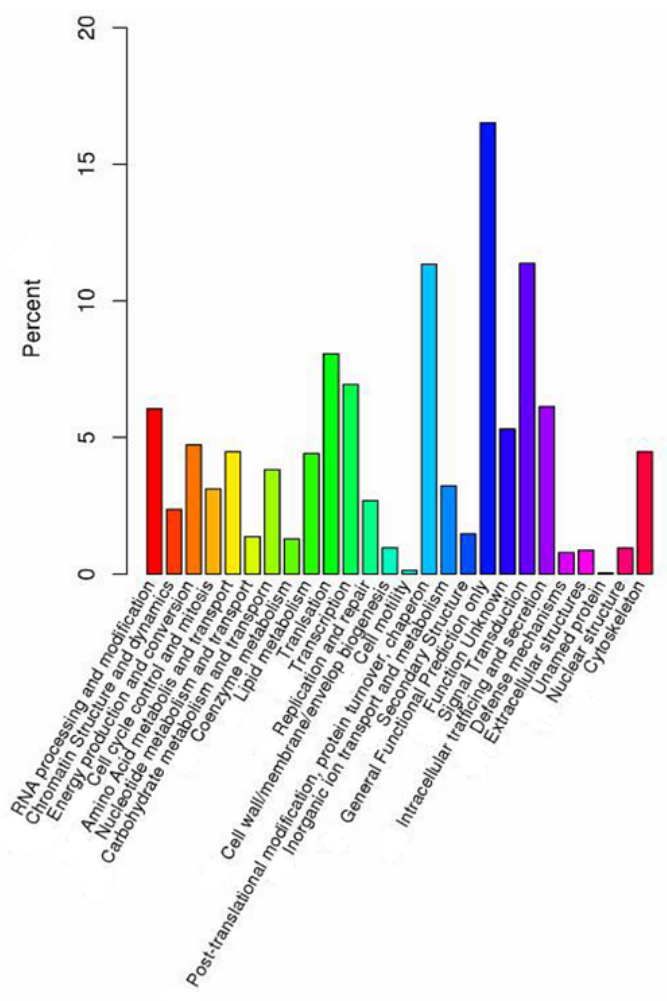

Figure 2. KOG classification of putative proteins.

According to the KEGG pathways of gene participation, 12,722 unigenes were assigned to five specific categories, including cellular processes, environmental information processing, genetic information processing, metabolism, and organism systems (Table 2). Metabolism pathways contained most unigenes $(4831,37.68 \%)$, with the majority being involved in carbohydrate metabolism, amino acid metabolism, and energy metabolism.

\section{Different expression analysis of genes}

Among all the annotated unigenes, using the filter criteria q-value $<0.005$ combined with an absolute fold change $>2,623$ unigenes were found to be differently expressed between LA and HA. These included 459 unigenes that were down-regulated and 164 unigenes that were up-regulated (Figure 3). The top three enriched GO terms were structural constituent of cuticle, oxidation-reduction process, and oxidoreductase activity in the degree of enrichment (Figure 4). 
Table 2. KEGG classification of unigenes.

\begin{tabular}{|c|c|c|}
\hline KEGG category & KEGG subcategory & No. of unigenes \\
\hline \multirow[t]{4}{*}{ Cellular processes } & Cell communication & 300 \\
\hline & Cell growth and death & 367 \\
\hline & Cell motility & 171 \\
\hline & Transport and catabolism & 730 \\
\hline \multirow[t]{3}{*}{ Environmental information processing } & Membrane transport & 162 \\
\hline & Signal transduction & 935 \\
\hline & Signaling molecules and interaction & 96 \\
\hline \multirow[t]{4}{*}{ Genetic information processing } & Folding, sorting and degradation & 920 \\
\hline & Replication and repair & 252 \\
\hline & Transcription & 553 \\
\hline & Translation & 1216 \\
\hline \multirow[t]{11}{*}{ Metabolism } & Amino acid metabolism & 776 \\
\hline & Biosynthesis of other secondary metabolites & 78 \\
\hline & Carbohydrate metabolism & 965 \\
\hline & Energy metabolism & 768 \\
\hline & Glycan biosynthesis and metabolism & 243 \\
\hline & Lipid metabolism & 559 \\
\hline & Metabolism of cofactors and vitamins & 418 \\
\hline & Metabolism of other amino acids & 283 \\
\hline & Metabolism of terpenoids and polyketides & 134 \\
\hline & Nucleotide metabolism & 417 \\
\hline & Xenobiotics biodegradation and metabolism & 190 \\
\hline \multirow[t]{9}{*}{ Organismal systems } & Circulatory system & 165 \\
\hline & Development & 142 \\
\hline & Digestive system & 291 \\
\hline & Endocrine system & 473 \\
\hline & Environmental adaptation & 150 \\
\hline & Excretory system & 210 \\
\hline & Immune system & 398 \\
\hline & Nervous system & 285 \\
\hline & Sensory system & 75 \\
\hline
\end{tabular}

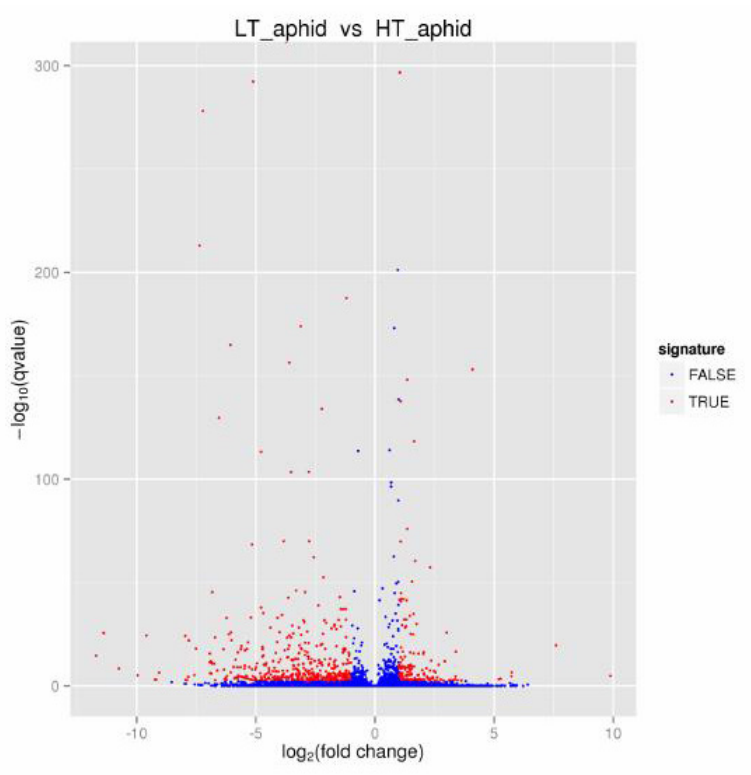

Figure 3. Analysis of differential gene expression between the LA and HA treatment groups. Blue dots represent individual genes that did not differ in expression, whereas red dots represent individual genes with differential expression among the treatment groups.

Genetics and Molecular Research 16 (1): gmr16019448 


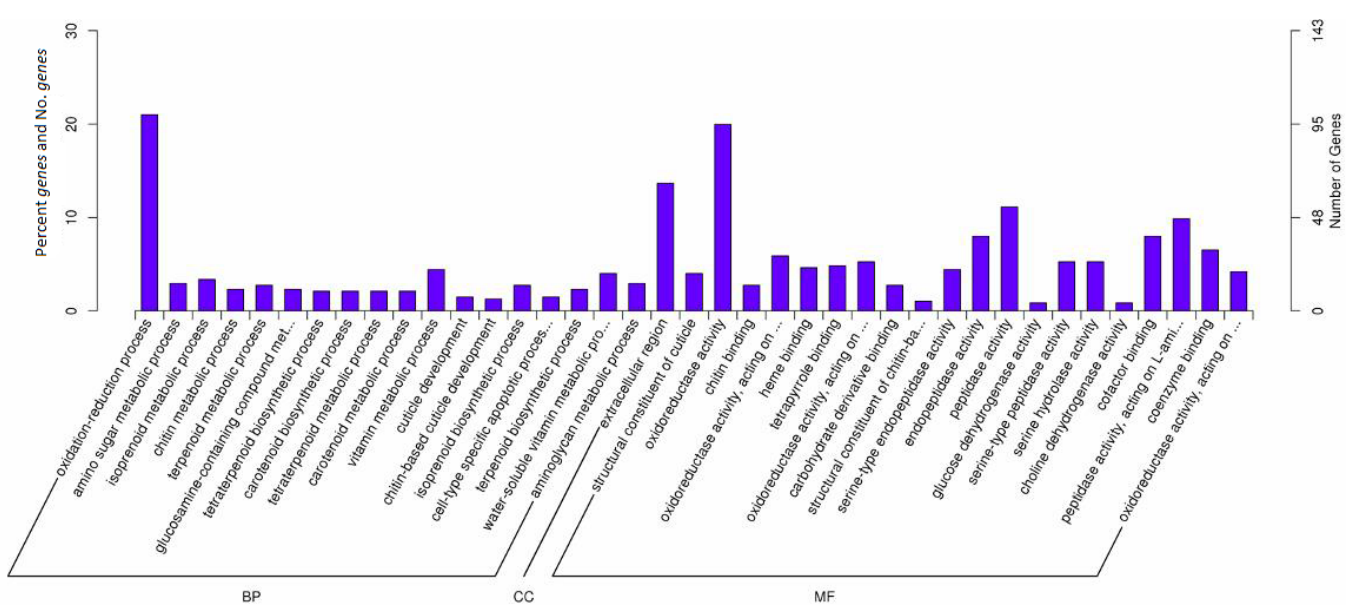

Figure 4. Enriched GO terms of the genes that were differentially expressed between the LA and HA treatment groups. BP: biological process; CC: cellular component; MF: Molecular Function.

In our analysis, we identified 51 genes with orthologs in Acyrthosiphon pisum (Nudel, orb, bicC, kelch, nanos, putative kelch-like, lodestar, gld2, gle1, pop2, cbp20, histone H2B.3, histone H1, suv4-20, uhrf1, cyclin J, clasp1, drp 1, arl6ip1, lsd1, six 4, and cbp 1) and Drosophila melanogaster (Sxl, tra, tra-2, ix, dsx, sis-a, gro, dpn, $f$ l, snf, da, DK, vir, doa, Rbpl, emc, os, run, her, STAT, SR, vitelline, yp1, yp2, yp3, ovo, fru, sex peptide, and esg) that are likely to have functions in $S$. chinensis reproduction determination. We found that 42 genes were expressed in wintering larvae, which have asexual or sexual individuals as offspring. Eight genes (nudel, gld2, histone H2B.3, SR, yp1, yp 3, ovo, and esg) were differently expressed between LA and HA (Table 3).

\section{qRT-PCR validation}

The gene expression profiles were validated by qRT-PCR and the results were closely consistent with the RNA-Seq results. The discrepancies in expression observed in a few genes between the qRT-PCR and RNA-Seq results may have been caused by a sensitivity bias between the two methods or by the use of different statistical methods and threshold values in the qRT-PCR and RNA-Seq.

\section{DISCUSSION}

Most aphids constantly rearrange their reproductive modes between sexual and asexual reproduction as an adaptation to the changing environment (Dixon, 1973; Lamb, 1992; Vorburger et al., 2003; Tagu et al., 2005; Gilabert et al., 2009; Sandrock et al., 2011). In our study, most $S$. chinensis larvae reared at low temperature $\left(7.5^{\circ} \mathrm{C}\right)$ developed into alate sexuparae $(\sim 89.6 \%)$ that migrate to the host-plant for sexual reproduction. By contrast, when larvae were reared at a high temperature $\left(18^{\circ} \mathrm{C}\right)$, only $5.3 \%$ developed into alate sexuparae, whereas the rest continued to reproduce parthenogenetically in the mosses. Moreover, no larvae developed into alate sexuparae when they were reared at $22^{\circ} \mathrm{C}$ (Table 1). This indicates 
Table 3. Description of the 42 transcripts/unigenes with predicted roles in reproduction determination.

\begin{tabular}{|c|c|c|c|}
\hline Similarity & Annotations & q value & |Fold-change| \\
\hline nudel $^{*}$ & Proteolysis//serine-type endopeptidase activity & $4.11 \mathrm{E}-06$ & 11.31 \\
\hline orb & Regulation of translation//synaptonemal complex assembly//regulation of neuronal synaptic plasticity & 0.83174 & 1.55 \\
\hline bicC & RNA binding & 0.14841 & 1.42 \\
\hline Kelch & $\begin{array}{l}\text { Developmental process involved in reproduction//anatomical structure formation involved in morphogenesis//organelle } \\
\text { organization//ovarian nurse cell to oocyte transport//cellular process involved in reproduction in multicellular organism } \\
\text { acyl-carrier-protein biosynthetic process }\end{array}$ & 0.99863 & 1.26 \\
\hline Nanos & Protein phosphorylation//DNA binding//ATP binding//protein binding//protein kinase activity//helicase & 0.17256 & 2.03 \\
\hline Lodestar & $\begin{array}{l}\text { Activity//binding//nucleic acid binding } \\
\text { Transferase activity }\end{array}$ & 0.99863 & 1.17 \\
\hline Gld2* & Taurine metabolic process//poly(A)+ mrna export from nucleus//leukotriene metabolic process//glutathione metabolic & $4.33 \mathrm{E}-05$ & 24.18 \\
\hline Gle 1 & $\begin{array}{l}\text { Process//prostaglandin metabolic process//viral transcription } \\
\text { Nucleic acid binding//nucleus }\end{array}$ & 0.99863 & 1.41 \\
\hline Pop2 & Nucleotide binding //zinc ion binding//nucleic acid binding & 0.99863 & 1.78 \\
\hline cbp20 & Nucleosome assembly//DNA-dependent transcription, initiation//DNA binding//protein heterodimerization & 0.99863 & 1.01 \\
\hline histone $H 2 B .3^{*}$ & $\begin{array}{l}\text { Activity//sequence-specific DNA binding } \\
\text { Nucleosome assembly//DNA binding//nucleus///chromosome//nucleosome }\end{array}$ & $8.63 \mathrm{E}-11$ & 2.76 \\
\hline histone $\mathrm{HI}$ & Cellular macromolecule metabolic process $/ /$ lysine catabolic process $/ /$ protein methylation//primary metabolic process & 0.010951 & 1.75 \\
\hline Suv4-20 & $\begin{array}{l}\text { Organ regeneration//maintenance of DNA methylation//regulation of transcription, DNA-dependent//protein } \\
\text { ubiquitination//lens development in camera-type eye//chromatin modification }\end{array}$ & 0.99863 & 1.17 \\
\hline uhrf1 & $\begin{array}{l}\text { Protein folding//DNA replication initiation//response to stress } \\
\text { Carbohydrate biosynthetic process }\end{array}$ & 0.99863 & 1.22 \\
\hline $\operatorname{cyclin} J$ & Small gtpase mediated signal transduction//GTP catabolic process & $4.31 \mathrm{E}-99$ & 1.57 \\
\hline clasp1 & DNA repair//DNA replication//regulation of transcription, DNA-dependent//DNA recombination & 0.99863 & 1.24 \\
\hline Drp-1 & Peptidoglycan biosynthetic process//nitrogen compound metabolic process//glutamine & 0.06549 & 1.56 \\
\hline Arl6ip1 & Biosynthetic process & 0.99863 & 1.17 \\
\hline Lsd-1 & RNA-dependent DNA replication, regulation of transcription, DNA-dependent//amino acid transport & 0.99863 & 1.27 \\
\hline pol protein & Phosphorylation//regulation of transcription, DNA-dependent//serine family amino acid metabolic process//protein & 0.99863 & 1.00 \\
\hline Six 4 & $\begin{array}{l}\text { Phosphorylation//cytokinesis } \\
\text { Positive regulation of mrna splicing, via spliceosome//regulation of alternative mrna splicing, via spliceosome }\end{array}$ & 0.99863 & 1.89 \\
\hline Sxl & Regulation of transcription from RNA polymerase II promoter & 0.99863 & 3.91 \\
\hline tra-2 & DNA repair//regulation of transcription, DNA-dependent//translational elongation//ribosome biogenesis//sex differentiation & 0.33145 & 1.87 \\
\hline$I x$ & Phosphorylation//angiogenesis//regulation of cell division//negative regulation of Wnt receptor signaling pathway//regulation & 0.99863 & 1.08 \\
\hline Dsx & $\begin{array}{l}\text { Of establishment of cell polarity//regulation of protein localization//positive regulation of gastrulation } \\
\text { Pantothenate biosynthetic process//beta-alanine metabolic process//regulation of transcription, dna-dependent }\end{array}$ & 0.99863 & 1.15 \\
\hline Gro & $\begin{array}{l}\text { Mrna splicing, via spliceosome//regulation of transcription from RNA polymerase II promoter//proteolysis } \\
\text { Lipid transport//viral reproduction } \\
\text { Transport//pathogenesis//ion channel inhibitor activity }\end{array}$ & 0.0046532 & 1.33 \\
\hline$\frac{d p n}{2}$ & Protein phosphorylation & 0.045305 & 8.44 \\
\hline snf & Mrna export from nucleus//mrna splicing, via spliceosome//insulin receptor signaling pathway//termination of RNA & 0.99863 & 1.09 \\
\hline$d a$ & Polymerase II transcription//mrna 3'-end processing//pathogenesis & 0.0047589 & 1.81 \\
\hline vir & Negative regulation of transcription, DNA-dependent & 0.99863 & 1.21 \\
\hline doa & Imaginal disc-derived female genitalia development//spermathecum morphogenesis//regulation of transcription, & 0.99863 & 1.70 \\
\hline Rbp 1 & $\begin{array}{l}\text { DNA-dependent//oogenesis///scab formation///sensory organ precursor cell fate determination//negative regulation of } \\
\text { transcription from RNA polymerase II promoter//regulation of transcription from RNA polymerase II promoter//positive }\end{array}$ & 0.99863 & 1.52 \\
\hline Emc & Regulation of compound eye retinal cell programmed cell death//lymph gland crystal cell differentiation//R7 cell & 0.18251 & 1.66 \\
\hline \multirow[t]{3}{*}{ Run } & $\begin{array}{l}\text { Development//embryonic crystal cell differentiation///ignal transduction//antennal development//positive regulation of } \\
\text { transcription from RNA polymerase II promoter//defense response//compound eye cone cell differentiation//regulation of }\end{array}$ & 0.99863 & 2.5 \\
\hline & Apoptotic process & & \\
\hline & $\begin{array}{l}\text { Signal transduction//regulation of transcription, DNA-dependent } \\
\text { Transport/DNA repair//intracellular signal transduction//pathogenesis//DNA binding//ion channel inhibitor activity//nucleic } \\
\text { acid binding//zinc ion binding } \\
\text { Catalytic activity }\end{array}$ & & \\
\hline STAT & Serine-type endopeptidase inhibitor activity & 0.39153 & 2.42 \\
\hline$S R^{*}$ & $\begin{array}{l}\text { Glycerolipid metabolic process//glycosphingolipid metabolic process// photosynthesis, light reaction//histidine biosynthetic } \\
\text { process//glycosaminoglycan catabolic process//DNA repair//galactose metabolic process//photosynthesis// DNA }\end{array}$ & 0.0013114 & 3.58 \\
\hline$y p 1^{*}$ & Binding//ATP binding//imidazoleglycerol-phosphate dehydratase activity//zinc ion binding//nucleic acid binding//nuclease & $6.56 \mathrm{E}-07$ & 3.52 \\
\hline$y p 3^{*}$ & Activity//metal ion binding//beta-galactosidase activity & $5.92 \mathrm{E}-06$ & 2.79 \\
\hline \multirow[t]{2}{*}{ ovo* } & Metabolic process//DNA binding//protein binding///zinc ion binding//binding //oxidoreductase activity & 0.00049941 & 2.92 \\
\hline & $\begin{array}{l}\text { G-protein coupled receptor signaling pathway//folic acid biosynthetic process//tetrahydrobiopterin biosynthetic } \\
\text { process//oxidation-reduction process }\end{array}$ & & \\
\hline Fru & $\begin{array}{l}\text { Glycerolipid metabolic process//glycosphingolipid metabolic process// photosynthesis, light reaction//histidine biosynthetic } \\
\text { process//glycosaminoglycan catabolic process//DNA repair//galactose metabolic process//photosynthesis }\end{array}$ & 0.99863 & 1.04 \\
\hline sex peptide receptor & & 0.99863 & 1.03 \\
\hline esg* & & 0.00049941 & 3.89 \\
\hline
\end{tabular}

*Genes expressed differently in two samples based on the filter criteria qvalue $<0.005 \& \mid$ Fold-change $\mid>2$.

that the rearing temperature not only affected the eclosion rate of sexuparae, but also the reproduction mode of the offspring.

Based on RNA-Seq technology, 84,280 unigenes with a mean length of $666 \mathrm{bp}$, ranging from 201 to $23,871 \mathrm{bp}$ were assembled. A comparison of the assembled unigenes

Genetics and Molecular Research 16 (1): gmr16019448 
to other insect species using BLAST analysis and functional annotation indicated that we had obtained an expansive and diverse gene expression set. Of the DEGs, 476 unigenes were annotated, while and 147 genes were not. The larvae that were reared under different temperature conditions, but same photoperiod and humidity, had diverged by adapting to the specific ambient conditions with respect to the different reproduction profiles observed in the two treatments. This raises the possibility that at least some of the 147 non-annotated unigenes were new genes that may be related to the ability of $S$. chinensis to respond to changes in temperature. In this study, almost all aphids reared at $7.5^{\circ} \mathrm{C}$ gave birth to male and female aphids, whereas aphids reared at $18^{\circ} \mathrm{C}$ reproduced parthenogenetically. We do not have any data on the unclassified 147 genes, and future studies should therefore address whether these genes are linked to aphid reproduction.

We found that there was no significant enrichment GO term related to reproduction. However, of 27 enriched unigenes involved in reproduction function, 21 were down-regulated and six were up-regulated unigenes. This means that 21 unigenes had a relatively higher expression in LA and only six unigenes had a relatively higher expression in HA.

The growth, development, reproduction, and other physiological and behavioral responses of insects cannot be completed without the participation of hormones. Estrogens and androgens are sex hormones that promote the maturity of reproductive organs and the development of secondary sexual characteristics of males and females. The estrogen and androgen metabolic process terms, which were absent in HA, were enriched in six unigenes found in LA. Similarly, there were 18 highly expressed unigenes in LA that were enriched for the terms insemination, sperm competition, sperm storage, spermatogenesis, oogenesis, sexual reproduction, sex differentiation, and ovarian follicle cell development in LA.

Aphids have the ability to produce three generations within one viviparous female, where the mature embryos developing inside the maternal abdomen carry the first developmental stage of the third generation (telescoping of generations) (Stevens, 1905). Therefore, two reproductive modes are present in these viviparous females: The second generation (all females) is produced parthenogenically inside the first generation of overwintering females, and the third generation (males and females) is produced sexually inside the second generation of females (Figure S1). This could explain why some enrichment terms related to sex differentiation and spermatogenesis were seen in LA but not in HA, which continue to reproduce parthenogenically.

In insects, some genes have specific functions in males and females whose functions are not controlled via transcriptional regulation but instead by sex-specific alternative splicing (Bell, 1988; Burtis and Baker, 1989; Hoshijima et al., 1991). Alternative splicing allows for protein diversity by producing more than one mature mRNA from a single pre-mRNA. In $D$. melanogaster, the mRNA precursors of Sxl, tra, and DSX are the same in males and females. However, after sex-specific splicing, they are processed into female and male-specific mRNAs. Since $S x l$ has several exons and introns, it can be spliced in different ways to result in different mRNAs. In honeybees (Lattorff et al., 2005; Jarosch et al., 2011), worker reproduction is regulated by the queen, brood pheromones, and worker policing. However, workers can evade these control mechanisms and activate their ovaries to produce diploid female offspring parthenogenetically. And the behaviours were influenced by alternative splicing of a gene homologue (thelytoky) to the transcription factor that controls worker sterility, which is located on chromosome 13. In our study, the expressions of $S x l$, tra, and $D S X$ at different temperatures in S. chinensis showed no differentiation. However, the downstream genes of Sxl, tra, and DSX

Genetics and Molecular Research 16 (1): gmr16019448 
as well as the sex differentiation genes ovo, yp1,yp3, and esg were differentially expressed. Using RNA-Seq technology we are able to observe differential expression of some genes, but we can gain no further information. To further our understanding, our next step will be to identify the sex-specific splicing, especially related to the three genes $(S x l$, tra, and DSX) that were differentially expressed in response to the two temperature conditions. In conclusion, this study will not only be helpful to identify the genes associated with reproduction determination in $S$. chinensis, but also to understand the mechanism of aphid reproductive determination.

\section{Conflicts of interest}

The authors declare no conflict of interest.

\section{ACKNOWLEDGMENTS}

The authors would like to acknowledge Prof. Kirst King-Jones for his helpful comments. Research supported by the Natural Sciences Foundation of China (\#U1402263; \#31370651; \#31372266), the National High-tech R\&D Program of China (“863” Program, \#2014AA021802), the China Scholarship Council, and the Grant for Essential Scientific Research of Chinese National Non-profit Institute (\#CAFYBB2014ZD005).

\section{REFERENCES}

Artacho P, Figueroa CC, Cortes PA, Simon JC, et al. (2011). Short-term consequences of reproductive mode variation on the genetic architecture of energy metabolism and life-history traits in the pea aphid. J. Insect Physiol. 57: 986-994. http://dx.doi.org/10.1016/j.jinsphys.2011.04.013

Bell G (1988). Uniformity and diversity in the evolution of sex. In: The evolution of sex: An examination of current ideas (Michod RE and Levin BR, eds.). Sinauer Associates, Sunderland, 126-138.

Burtis KC and Baker BS (1989). Drosophila doublesex gene controls somatic sexual differentiation by producing alternatively spliced mRNAs encoding related sex-specific polypeptides. Cell 56: 997-1010. http://dx.doi. org/10.1016/0092-8674(89)90633-8

Benjamini Y and Hochberg Y (1995). Controlling the false discovery rate: a practical and powerful approach to multiple testing. J. Roy. Statist. Ser. B, (57): 289-300.

Dixon AFG (1973). Biology of aphids. Edward Arnold, London.

Gilabert A, Simon JC, Mieuzet L, Halkett F, et al. (2009). Climate and agricultural context shape reproductive mode variation in an aphid crop pest. Mol. Ecol. 18: 3050-3061. http://dx.doi.org/10.1111/j.1365-294X.2009.04250.x

Grabherr MG, Haas BJ, Yassour M, Levin JZ, et al. (2011). Full-length transcriptome assembly from RNA-Seq data without a reference genome. Nat. Biotechnol. 29: 644-652. http://dx.doi.org/10.1038/nbt.1883

Hoshijima K, Inoue K, Higuchi I, Sakamoto H, et al. (1991). Control of doublesex alternative splicing by transformer and transformer-2 in Drosophila. Science 252: 833-836. http://dx.doi.org/10.1126/science.1902987

Jarosch A, Stolle E, Crewe RM and Moritz RFA (2011). Alternative splicing of a single transcription factor drives selfish reproductive behavior in honeybee workers (Apis mellifera). Proc. Natl. Acad. Sci. USA 108: 15282-15287. http:// dx.doi.org/10.1073/pnas. 1109343108

Kanehisa M, Araki M, Goto S, Hattori M, et al. (2008). KEGG for linking genomes to life and the environment. Nucleic Acids Res. 36: D480-D484. http://dx.doi.org/10.1093/nar/gkm882

Koenig D, Jiménez-Gómez JM, Kimura S, Fulop D, et al. (2013). Comparative transcriptomics reveals patterns of selection in domesticated and wild tomato. Proc. Natl. Acad. Sci. USA 110: E2655-E2662. http://dx.doi.org/10.1073/ pnas. 1309606110

Lamb RJ (1992). Developmental rate of Acyrthosiphon pisum (Homoptera, Aphididae) at low temperatures: implications for estimating rate parameters for insects. Environ. Entomol. 21: 10-19. http://dx.doi.org/10.1093/ee/21.1.10

Lattorff HMG, Moritz RF and Fuchs S (2005). A single locus determines thelytokous parthenogenesis of laying honeybee workers (Apis mellifera capensis). Heredity (Edinb) 94: 533-537. http://dx.doi.org/10.1038/sj.hdy.6800654

Genetics and Molecular Research 16 (1): gmr16019448 
Li B and Dewey CN (2011). RSEM: accurate transcript quantification from RNA-Seq data with or without a reference genome. BMC Bioinformatics 12: 323. http://dx.doi.org/10.1186/1471-2105-12-323

Liu P, Yang ZX, Chen XM and Foottit RG (2014). The effect of the gall-forming aphid Schlechtendalia chinensis (Hemiptera: Aphididae) on leaf wing ontogenesis in Rhus chinensis (Sapindales: Anacardiaceae). Ann. Entomol. Soc. Am. 107: 245-250. http://dx.doi.org/10.1603/AN13118

Malone JH and Oliver B (2011). Microarrays, deep sequencing and the true measure of the transcriptome. BMC Biol. 9: 34. http://dx.doi.org/10.1186/1741-7007-9-34

Mao X, Cai T, Olyarchuk JG and Wei L (2005). Automated genome annotation and pathway identification using the KEGG Orthology (KO) as a controlled vocabulary. Bioinformatics 21: 3787-3793. http://dx.doi.org/10.1093/ bioinformatics/bti430

Nagalakshmi U, Wang Z, Waern K, Shou C, et al. (2008). The transcriptional landscape of the yeast genome defined by RNA sequencing. Science 320: 1344-1349. http://dx.doi.org/10.1126/science.1158441

Ozsolak F and Milos PM (2011). RNA sequencing: advances, challenges and opportunities. Nat. Rev. Genet. 12: 87-98. http://dx.doi.org/10.1038/nrg2934

Sandrock C, Razmjou J and Vorburger C (2011). Climate effects on life cycle variation and population genetic architecture of the black bean aphid, Aphis fabae. Mol. Ecol. 20: 4165-4181. http://dx.doi.org/10.1111/j.1365-294X.2011.05242.x

Shao SX, Yang ZX and Chen XM (2013). Gall development and clone dynamics of the galling aphid Schlechtendalia chinensis (Hemiptera: Pemphigidae). J. Econ. Entomol. 106: 1628-1637. http://dx.doi.org/10.1603/EC13114

Stevens NM (1905). A study of the germ cells of Aphis rosae and Aphis oenotherae. J. Exp. Zool. 2: 313-333. http://dx.doi. org/10.1002/jez.1400020302

Sultan M, Schulz MH, Richard H, Magen A, et al. (2008). A global view of gene activity and alternative splicing by deep sequencing of the human transcriptome. Science 321: 956-960. http://dx.doi.org/10.1126/science.1160342

Tagu D, Sabater-Muñoz B and Simon JC (2005). Deciphering reproductive polyphenism in aphids. Invertebr. Reprod. Dev. 48: 71-80. http://dx.doi.org/10.1080/07924259.2005.9652172

Tang J and Cai BH (1957). Studies on the Chinese gallnuts of Meitan, Kweichow. Acta Entomol. Sin 7: 131-140.

Vorburger C, Lancaster M and Sunnucks P (2003). Environmentally related patterns of reproductive modes in the aphid Myzus persicae and the predominance of two 'superclones' in Victoria, Australia. Mol. Ecol. 12: 3493-3504. http:// dx.doi.org/10.1046/j.1365-294X.2003.01998.x

Young MD, Wakefield MJ, Smyth GK and Oshlack A (2010). Gene ontology analysis for RNA-seq: accounting for selection bias. Genome Biol. 11: R14. http://dx.doi.org/10.1186/gb-2010-11-2-r14

Zhang CX, Xu H and Tang J (1993). Influence of temperature on polymorphism of the overwintering generation of Chinese horned gall aphid, Schlechtendalia chinensis (Bell). Entomol. Sin. 36: 497-499.

Zhang GX and Zhong TS (1983). The economic insect fauna of China. Science Press, Beijing.

Zhang GX, Qiao GX, Zhong TS and Zhang WY (1999). Fauna Sinica, Insecta Vol. 14 Homoptera, Mindaridae and Pemphigidae. Science Press, Beijing.

Zhang ZH (1987). The processing and utilization technology in Chinese gallnuts. China Forestry Press, Beijing.

\section{Supplementary material}

Figure S1. The 'telescoping of generations' phenomenon in S. chinensis.

Genetics and Molecular Research 16 (1): gmr16019448 